
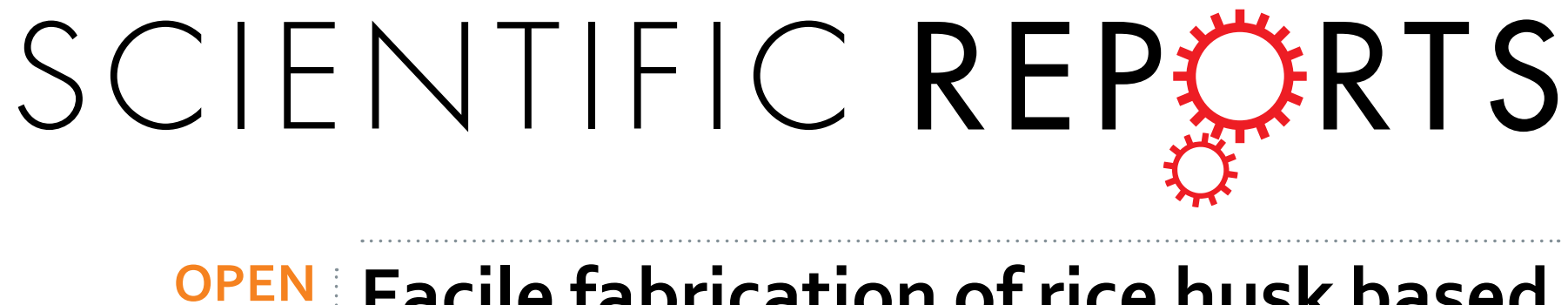

Facile fabrication of rice husk based silicon dioxide nanospheres loaded with silver nanoparticles as a rice

Received: 01 October 2015

Accepted: 07 January 2016

Published: 18 February 2016

\section{antibacterial agent}

\author{
Jianghu Cui ${ }^{1,2}$, You Liang ${ }^{3}$, Desong Yang ${ }^{3}$ \& Yingliang Liu ${ }^{1}$
}

Bacterial leaf blight of rice caused by Xanthomonas oryzae pv. oryzae (Xoo) is a major disease of rice, leading to reduction in production by $10-50 \%$. In order to control this disease, various chemical bactericides have been used. Wide and prolonged application of chemical bactericides resulted in the resistant strain of $X o o$ that was isolated from rice. To address this problem, we were searching for an environmentally friendly alternative to the commonly used chemical bactericides. In this work, we demonstrate that silicon dioxide nanospheres loaded with silver nanoparticles $\left(\mathrm{SiO}_{2}-\mathrm{Ag}\right) \mathrm{can}$ be prepared by using rice husk as base material precursor. The results of the antibacterial tests showed that $\mathrm{SiO}_{2}-\mathrm{Ag}$ composites displayed antibacterial activity against $\mathrm{Xoo}$. At cellular level, the cell wall/ membrane was damaged and intercellular contents were leaked out by slow-releasing of silver ions from $\mathrm{SiO}_{2}$ - $\mathrm{Ag}$ composites. At molecular level, this composite induced reactive oxygen species production and inhibited DNA replication. Based on the results above, we proposed the potential antibacterial mechanism of $\mathrm{SiO}_{2}$-Ag composites. Moreover, the cytotoxicity assay indicated that the composites showed mild toxicity with rice cells. Thus, this work provided a new strategy to develop biocide derived from residual biomass.

Rice (Oryza sativa L.) is an important cultivated food crop worldwide. It accounts for more than $20 \%$ of the world's crop productions and feeds approximately $50 \%$ of the world's population ${ }^{1}$. Bacterial blight, blast and sheath blight are the three most destructive diseases affecting rice ${ }^{2-5}$. Bacterial leaf blight is caused by Xanthomonas oryzae pv. oryzae (Xoo), and it can lead to a $10-50 \%$ reduction in crop yield. Various chemical bactericides have been used to control the infection and spread of Xoo, such as bismerthiazol and streptomycin ${ }^{6,7}$. Long-term and excessive exposure to the chemical bactericides have induced resistance in the bacteria, widespread instances of poor treatment efficacy and large economic losses ${ }^{8}$.

To solve this problem, scientists have been searching for several new antibacterial agents as alternatives to synthetic chemical bactericides. Various nanoparticles have been investigated for plant disease management, such as graphene oxide ${ }^{9,10}$, sulfur ${ }^{11}, \mathrm{TiO}_{2}{ }^{12}, \mathrm{ZnO}^{13}$, and $\mathrm{Cu}$ nanoparticles ${ }^{14}$. In particular, silver nanoparticles (Ag NPs) have attracted considerable attention due to their wide antibacterial spectrum compared to other nanomaterials $\mathrm{s}^{8,15,16}$. Unfortunately, Ag NPs less than $20 \mathrm{~nm}$ in diameter tend to aggregate and oxidize, leading to a decrease in their antibacterial performance ${ }^{17-19}$. In addition, Ag NPs have been reported to have negative impacts or potential toxicities in plants ${ }^{20,21}$. Hence, there is a compelling need to improve the antibacterial activity and develop a valid strategy to reduce the toxicity of Ag NPs. Recent studies have shown that a wide range of base materials can be used to synthesize antibacterial composites with Ag NPs, including carbon nanotubes ${ }^{22}$, cellulose nanocrystals ${ }^{23}$ and graphene ${ }^{24}$. Our group also prepared some composites, such as carbon nanospheres ${ }^{25}$ and porous carbon ${ }^{26}$ loaded with Ag NPs. However, these materials require complex and expensive preparation methods. Therefore, the design of base materials with low cost and simple processing presents a significant challenge.

${ }^{1}$ College of Materials and Energy, South China Agricultural University, Guangzhou 510642, Guang dong, P. R. China. ${ }^{2}$ Guangdong Key Laboratory of Agricultural Environment Pollution Integrated Control, Guangdong Institute of Eco-Environmental and Soil Sciences, Guangzhou 510650, P. R. China. ${ }^{3}$ College of Agriculture, Shihezi University, Shihezi 832000 , Xinjiang, P. R. China. Correspondence and requests for materials should be addressed to D.Y. (email: yds_agr@shzu.edu.cn)orY.L. (email: tliuyl@scau.edu.cn) 


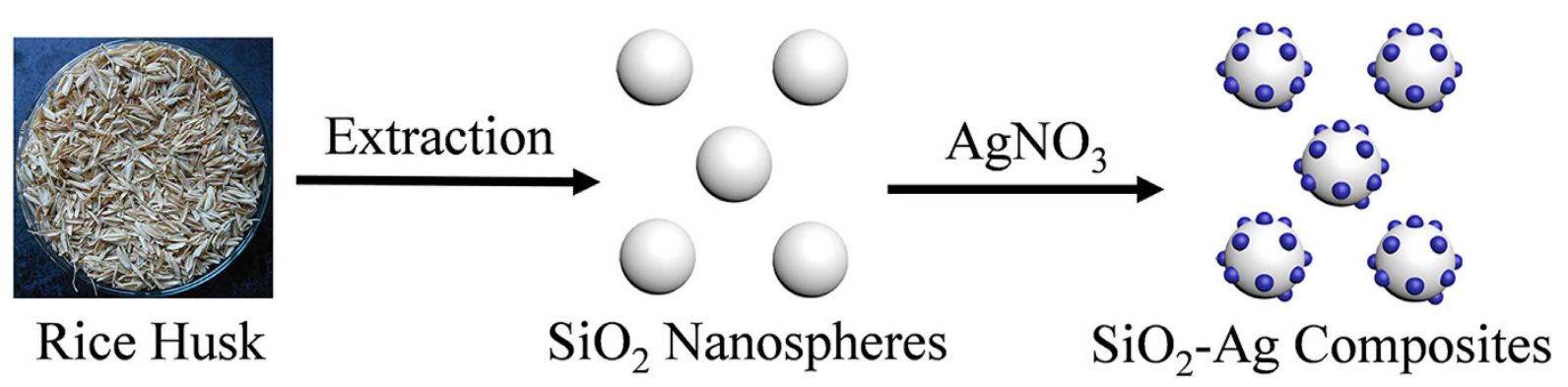

Figure 1. Schematic illustration of the formation of $\mathrm{Ag} \mathrm{NPs} \mathrm{immobilized} \mathrm{on} \mathrm{SiO}_{2}$ nanospheres. White sphere and blue points stand for $\mathrm{SiO}_{2}$ nanospheres and $\mathrm{Ag}$ NPs, respectively.

Rice husk is a commonly agricultural waste material and the world annual production is approximately 120 million tons ${ }^{27}$. It is reported that rice husk contains approximately $20 \%$ silicon dioxide, which makes it a potential renewable source of $\mathrm{SiO}_{2}{ }^{28}$. And previous researches have indicated that $\mathrm{SiO}_{2}$ nanoparticles can decrease heavy metal accumulation and increase the production of the plant ${ }^{29,30}$. Meanwhile, $\mathrm{SiO}_{2}$ nanospheres have high surface and reactivity and are considered as a supporting material according to the previous study ${ }^{31}$. So we use rice husk as a raw material to prepare $\mathrm{SiO}_{2}$ nanosphere, which is a suitable candidates for supporting material.

In our work, we developed a simple method to synthesize $\mathrm{SiO}_{2}$ nanospheres using rice husk as a raw material and decorated the nanospheres with Ag NPs by the reduction of Ag ions. The results showed that the Ag NPs were successfully loaded onto the surface of the $\mathrm{SiO}_{2}$ nanospheres $\left(\mathrm{SiO}_{2}-\mathrm{Ag}\right)$, and the preliminary studies showed that the composites have a superior antibacterial effect and only mild cytotoxicity to rice cells. Furthermore, the level of reactive oxygen species (ROS), the content of genomic DNA and the integrity of the cell membrane were also determined. Based on the results above, we proposed a potential antibacterial mechanism of the $\mathrm{SiO}_{2}-\mathrm{Ag}$ composites. In general, this study provides direct evidence that these composites have great potential to be used as antibacterial agents in agriculture and offer an environmentally friendly method to synthesize an antibacterial nanomaterial using residual biomass.

\section{Results and Discussion}

Synthesis and characterization of the $\mathrm{SiO}_{2}-\mathrm{Ag}$ composites. The synthesis process for the $\mathrm{SiO}_{2}-\mathrm{Ag}$ composites is shown in Fig. 1. In this study, we used rice husks as a raw material to synthesize $\mathrm{SiO}_{2}$ nanomaterials by a hydrothermal method. $\mathrm{SiO}_{2}$ was a near-perfect sphere with a smooth surface and a diameter of approximately $400 \mathrm{~nm}$ (Fig. 2A,C). Then, poly-(N-vinyl-2-pyrrolidone) (PVP) was applied as the stabilizer and reductant. The $\mathrm{Ag}$ ions were reduced at the surface of $\mathrm{SiO}_{2}$ nanospheres, and the typical morphology of the $\mathrm{SiO}_{2}$ - $\mathrm{Ag}$ composites is shown in Fig. 2B,D,E. We propose that the bulges on the $\mathrm{SiO}_{2}$ nanospheres are Ag NPs.

We performed high- resolution TEM (HRTEM) (Fig. 2E,F) to further analyze the nanostructures of the $\mathrm{SiO}_{2}$-Ag composites and found that the diameter of the Ag NPs was approximately $10 \mathrm{~nm}$. This small size of the Ag NPs might have better antibacterial activity ${ }^{32,33}$. The interplanar spacing for the lattice fringes was approximately $0.23 \mathrm{~nm}$, corresponding to the (111) lattice plane of silver ${ }^{34,35}$. The elemental composition of the $\mathrm{SiO}_{2}-\mathrm{Ag}$ composites was analyzed by energy dispersive X-ray spectroscopy (EDS), as shown in Fig. 2H; several types of peaks were clearly observed, which correspond to carbon, oxygen, copper, silicon, and silver. The as-prepared $\mathrm{SiO}_{2}-\mathrm{Ag}$ composites contain approximately $57.26 \mathrm{wt} \% \mathrm{Si}$ and $5.47 \mathrm{wt} \% \mathrm{Ag}$.

The structural features of the $\mathrm{SiO}_{2}$ - $\mathrm{Ag}$ composites have also been investigated by X-ray diffraction (XRD) analysis (Fig. 3). As shown in Fig. 3A, the typical XRD pattern of $\mathrm{SiO}_{2}$ nanospheres was an amorphous peak with the equivalent Bragg angle at $2 \theta=22^{\circ}$. Figure $3 \mathrm{~B}$ indicates that the $\mathrm{XRD}$ pattern of the $\mathrm{SiO}_{2}-\mathrm{Ag}$ composites has two sharp Bragg peaks at $38.2^{\circ}, 44.4^{\circ}$ in the $2 \theta$ region, which could be assigned to the (111) and (200) planes of silver, indicating that Ag NPs were successfully loaded onto the surface of the $\mathrm{SiO}_{2}$ nanospheres.

Release property. An inductively multitype coupled plasma emission spectrometer (ICP-AES) was used to compare the release rate of $\mathrm{Ag}$ ions from $\mathrm{AgNO}_{3}, \mathrm{Ag} \mathrm{NPs}$ and the $\mathrm{SiO}_{2}-\mathrm{Ag}$ composites. As shown in Fig. 4A, the $\mathrm{Ag}$ ions were completely released into the ultrapure water from $\mathrm{AgNO}_{3}$ and the $\mathrm{Ag} \mathrm{NPs}$ in less than 3-10 d. However, the $\mathrm{SiO}_{2}-\mathrm{Ag}$ composites could stably release $\mathrm{Ag}$ ions over $30 \mathrm{~d}$. The Ag ion release rate of the composites was slower than that of $\mathrm{AgNO}_{3}$ and the Ag NPs. After $30 \mathrm{~d}$, the $\mathrm{SiO}_{2}-\mathrm{Ag}$ composites had released $68.1 \%$ of the $\mathrm{Ag}$ ions, which was significantly lower than $\mathrm{AgNO}_{3}$ (96.4\%) and the Ag NPs (78.8\%). The results showed that the $\mathrm{SiO}_{2}-\mathrm{Ag}$ composites have a lower release speed than $\mathrm{AgNO}_{3}$ and the Ag NPs, which had more long-term antibacterial effects than that of $\mathrm{AgNO}_{3}$ and $\mathrm{Ag} \mathrm{NPs}{ }^{36,37}$.

Antibacterial evaluation. To confirm the antibacterial effect of the $\mathrm{SiO}_{2}$-Ag composites, the growth inhibition of the tested bacteria Xoo was investigated by the disk diffusion method. As shown in Fig. 4B, Ag NPs and $\mathrm{SiO}_{2}-\mathrm{Ag}$ composites have an average diameter of the inhibition zone of $18 \pm 2 \mathrm{~mm}$ and $23 \pm 1 \mathrm{~mm}$, respectively. However, the disks with the control and $\mathrm{SiO}_{2}$ nanospheres have no inhibition zone, indicating that the Ag NPs are the effective antibacterial component of the $\mathrm{SiO}_{2}-\mathrm{Ag}$ composites. Minimum inhibitory concentration (MIC) testing against Xoo was carried out to further evaluate the antibacterial activity of the $\mathrm{SiO}_{2}-\mathrm{Ag}$ composites. As shown in Fig. 5, the density of bacterial growth was decreased in a dose-dependent manner. Xoo growth was completely 

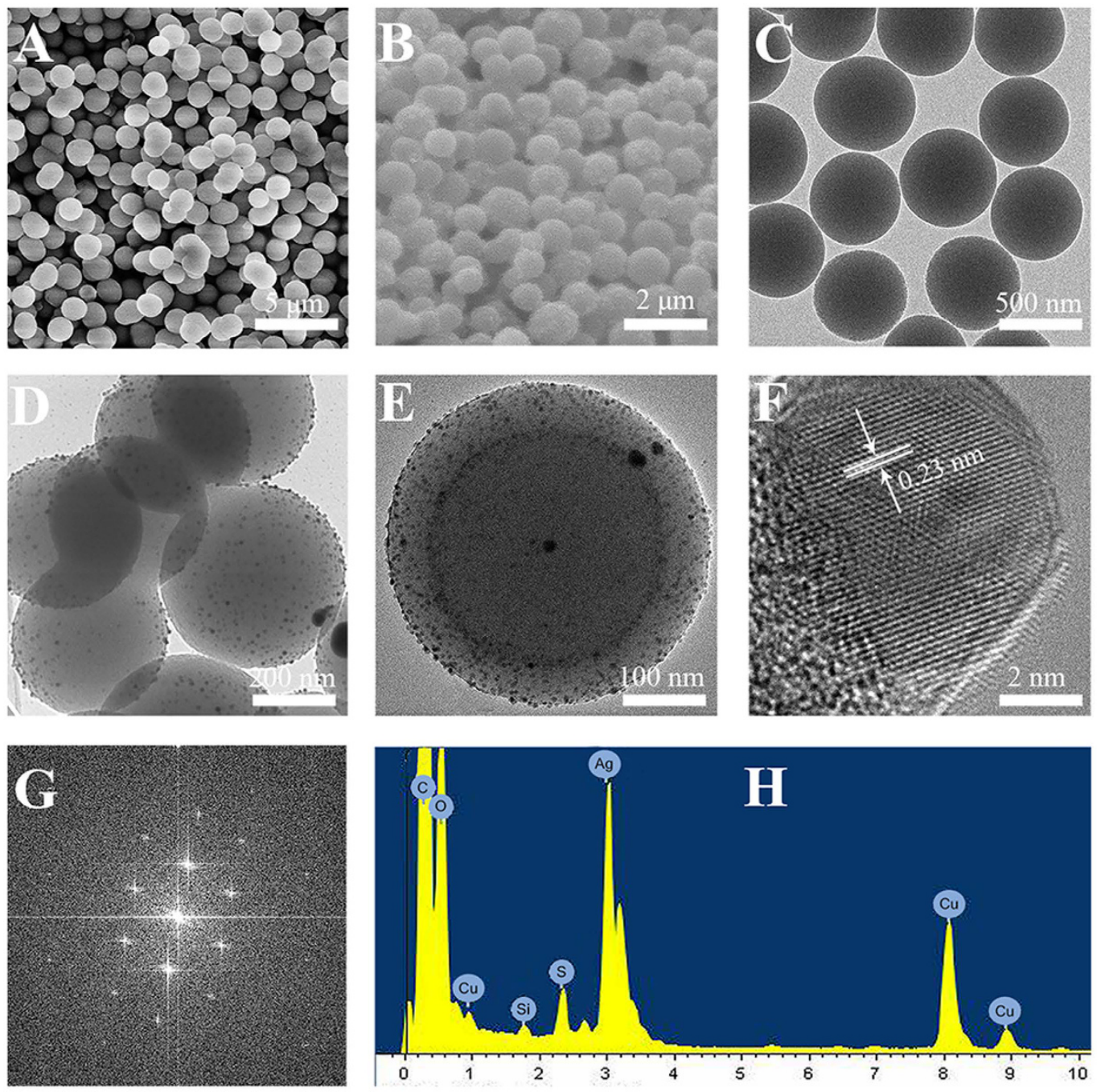

Figure 2. The characterization of $\mathrm{SiO}_{2}$ nanospheres and $\mathrm{SiO}_{2}-\mathrm{Ag}$ composites. Scanning electron microscopy (SEM) images of $\mathrm{SiO}_{2}$ nanospheres (A), $\mathrm{SiO}_{2}$ - Ag composites (B); Transmission electron microscope (TEM) images of $\mathrm{SiO}_{2}$ nanospheres (C) and $\mathrm{SiO}_{2}$-Ag composites (D); HRTEM images of $\mathrm{SiO}_{2}$-Ag composites (E) and $\mathrm{Ag}$ NPs (F); Fast fourier transform images of $\mathrm{Ag} \mathrm{NPs}(\mathbf{G})$; $\mathrm{EDS}$ of $\mathrm{SiO}_{2}-\mathrm{Ag}$ composites (H).
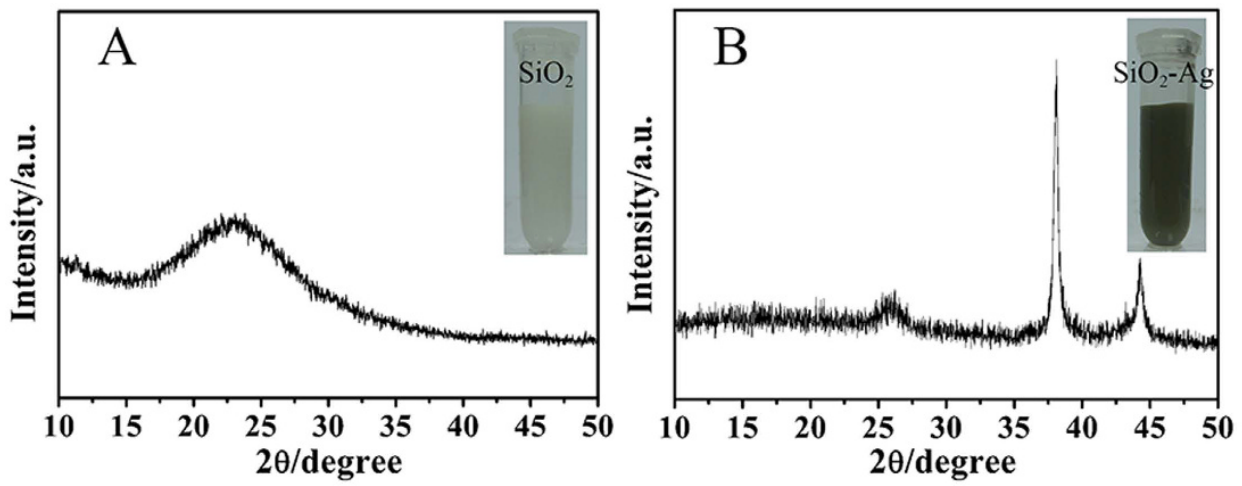

Figure 3. XRD patterns of $\mathrm{SiO}_{2}$ nanospheres (A) and $\mathrm{SiO}_{2}-\mathrm{Ag}$ composites (B). 

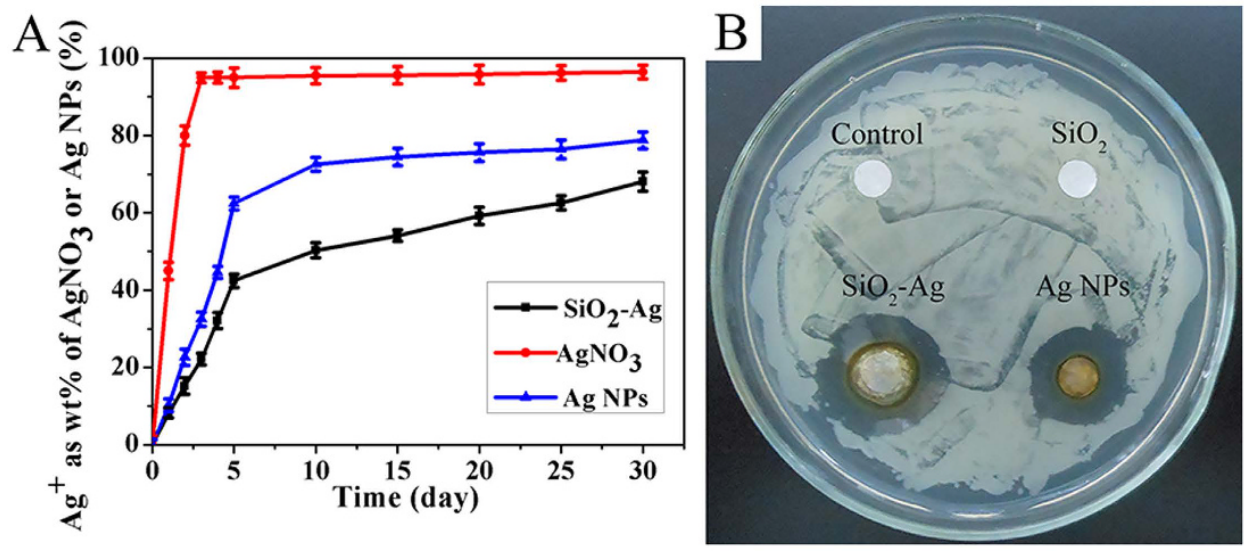

Figure 4. (A) Release of $\mathrm{Ag}$ ions from $\mathrm{AgNO}_{3}, \mathrm{Ag} \mathrm{NPs}$ and $\mathrm{SiO}_{2}-\mathrm{Ag}$ composites at $37^{\circ} \mathrm{C}$. (B) Zone of inhibition for control, $\mathrm{SiO}_{2}$ nanospheres, $\mathrm{Ag} \mathrm{NPs}$ and $\mathrm{SiO}_{2}-\mathrm{Ag}$ composites against Xoo.

inhibited when the concentration of the $\mathrm{SiO}_{2}$ - $\mathrm{Ag}$ composites was $3.2 \mu \mathrm{g} / \mathrm{mL}$ (Fig. 5J), whereas the Ag NP solution exhibited the same effect at a concentration of $12.5 \mu \mathrm{g} / \mathrm{mL}$ (Fig. 5A). The tests of the antibacterial properties confirmed that the antibacterial activity of the $\mathrm{SiO}_{2}-\mathrm{Ag}$ composites was approximately four times higher than that of the Ag NPs against Xoo.

The ability of $\mathrm{SiO}_{2}-\mathrm{Ag}$ to prevent viable bacteria growth is also demonstrated by fluorescence staining. Ethidium bromide $(\mathrm{EB})$ and acridine orange $(\mathrm{AO})$ were used as live/dead coloring agents. EB could enter through the damaged cell membrane and selectively stain dead cells, whereas AO could penetrate live and dead cells ${ }^{25,38}$. As shown in Fig. 6, nearly all of bacteria were viable when cultured on the control and $\mathrm{SiO}_{2}-\mathrm{Ag}$ composites. In contrast, the Xoo treated with the $\mathrm{SiO}_{2}$-Ag composites exhibited strong red fluorescence, indicating that most of the bacteria were killed (Fig. 6C). These results further support the antibacterial studies that the $\mathrm{SiO}_{2}$ - $\mathrm{Ag}$ composites were clearly more effective than the Ag NPs.

Cell wall/membrane integrity assay. A TEM study was performed to observe the morphological changes of bacteria cells after treatment with the $\mathrm{SiO}_{2}-\mathrm{Ag}$ composites. As shown in Fig. 7A,B, the bacteria were adsorbed by the $\mathrm{SiO}_{2}$-Ag composites, and the morphology of bacteria cells changed from cylindrical to spherical after treatment with the $\mathrm{SiO}_{2}-\mathrm{Ag}$ composites for $2 \mathrm{~h}$. Figure 7C,D illustrate that released Ag ions disrupted the cell wall/ membrane integrity. As a result, more Ag NPs were internalized into the bacteria cell wall/membrane, and the contents of the cell leaked out, leading to protein denaturation and cell death.

The antibacterial results demonstrate that the $\mathrm{SiO}_{2}-\mathrm{Ag}$ composites have better antibacterial properties compared to those of the Ag NPs. According to the literature, the antibacterial activity of Ag NPs would be reduced due to aggregation and oxidation ${ }^{17-19}$. In our work, we prepared the composites such that the Ag NPs were loaded on the surface of the $\mathrm{SiO}_{2}$ nanospheres. These composites could effectively enhance the antibacterial activity by preventing the aggregation and oxidation of Ag NPs and by continuously releasing Ag ions. This result was consistent with previous studies ${ }^{25,39}$. The $\mathrm{SiO}_{2}$ - Ag composites have a large surface area and high adsorption properties; thus, the bacteria could be easily adsorbed by the composites.

Intracellular oxidative stress. It has been suggested that the production of ROS is the common pathway by which antibacterial agents induce oxidative damage in bacteria cells ${ }^{40}$. Many nanomaterials have been reported to exert their toxic effects through $\mathrm{ROS}^{41-43}$. Therefore, we compared the level of ROS after treatment with $\mathrm{SiO}_{2}$ nanospheres, $\mathrm{Ag} \mathrm{NPs}$ and the $\mathrm{SiO}_{2}$-Ag composites by fluorescence intensity. As shown in Fig. 8A, the DCF fluorescence intensity in samples treated with $\mathrm{SiO}_{2}$ nanospheres was similar to that in the untreated cells. However, in the presence of the Ag NPs, the DCF fluorescence intensity was increased two-fold compared with exposure to the $\mathrm{SiO}_{2}$ nanospheres and to untreated cells. In addition, the DCF fluorescence intensity of the samples treated with the $\mathrm{SiO}_{2}$ - Ag composites was nearly 1.4 times higher than that of the samples treated with Ag NPs. These results revealed that the $\mathrm{SiO}_{2}$ - $\mathrm{Ag}$ composites could significantly increase ROS production and lead to cell damage. Moreover, the $\mathrm{SiO}_{2}-\mathrm{Ag}$ composites would have a long-term antibacterial effect by continually releasing $\mathrm{Ag}$ ions.

Influence of $\mathrm{SiO}_{2}-\mathrm{Ag}$ composites on genomic DNA. It has been reported that $\mathrm{Ag}$ NPs interact with DNA and inhibit DNA replication, resulting in rapid antibacterial activity ${ }^{44,45}$. In this study, agarose gel electrophoresis analysis was used to investigate the possible antibacterial mechanism of the $\mathrm{SiO}_{2}$ - $\mathrm{Ag}$ composites. As shown in Fig. 8B, the intensity of the genomic DNA band was decreased in a dose-dependent manner. The intensity of the genomic DNA band was lowest when the cells were treated with $12.5 \mu \mathrm{g} / \mathrm{mL}$ of $\mathrm{SiO}_{2}-\mathrm{Ag}$ composites. In contrast, the intensity of the genomic DNA band of the untreated cells formed a clear band. The results of agarose gel electrophoresis analysis were consistent with the MIC values. According to the above results, the potential antibacterial mechanism of the $\mathrm{SiO}_{2}$ - Ag composites was proposed as follows (Fig. 9): the bacterial cells absorb on the surface of the $\mathrm{SiO}_{2}-\mathrm{Ag}$ composites by electrostatic forces, and Ag ions were released from the Ag NPs and transported to the cytoplasm. The Ag ions directly interact with intracellular mitochondria, resulting in the 


\section{$12.5 \mu \mathrm{g} / \mathrm{mL} \quad 6.25 \mu \mathrm{g} / \mathrm{mL} \quad 3.2 \mu \mathrm{g} / \mathrm{mL} \quad 1.6 \mu \mathrm{g} / \mathrm{mL} \quad 0.8 \mu \mathrm{g} / \mathrm{mL} \quad 0.1 \mu \mathrm{g} / \mathrm{mL} \quad$ Control}

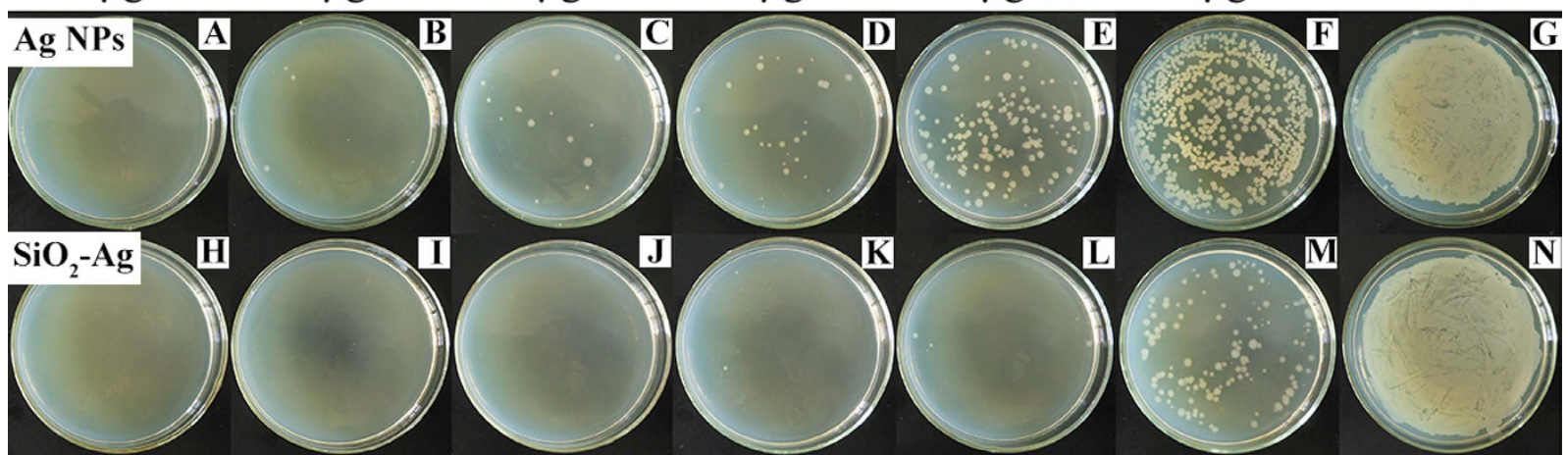

Figure 5. MIC of Ag NPs and $\mathrm{SiO}_{2}-\mathrm{Ag}$ composites against Xoo. The concentration of the antibacterial agents is shown on the top of each plate.
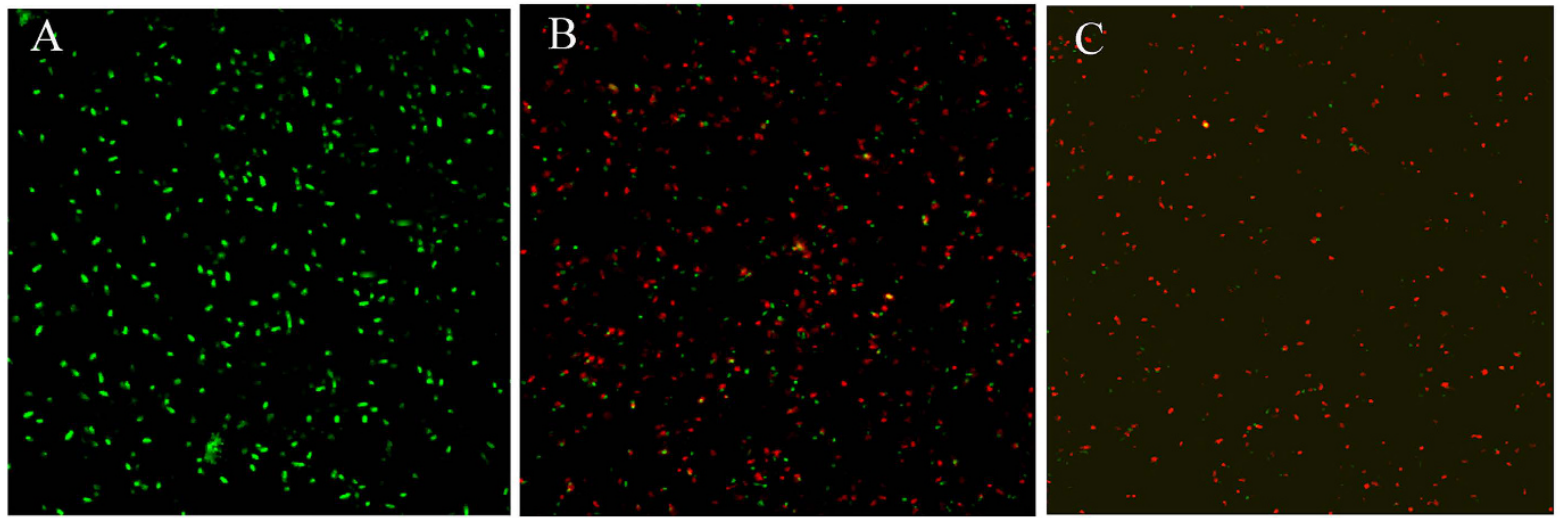

Figure 6. Confocal fluorescent microscopy images of live and dead Xoo cells after incubation with different samples. Fluorescence image of Xoo treated with control (A); Fluorescence image of Xoo treated with Ag NPs (B); Fluorescence image of Xoo treated with $\mathrm{SiO}_{2}$-Ag composites (C). Green spots represent live bacterial cells, whereas red fluorescence indicates dead bacteria.

generation of ROS and the inhibition of DNA replication. Subsequently, the integrity of the cell wall/membrane was disrupted, and the intracellular contents leaked out.

Cytotoxicity assay. To test the toxicity of the $\mathrm{SiO}_{2}$-Ag composites, we selected rice cell viability to elucidate the cellular response to a toxin. The rice cell suspension was exposed to different concentrations of $\mathrm{SiO}_{2}$ nanospheres, $\mathrm{Ag} \mathrm{NPs}$ or the $\mathrm{SiO}_{2}$ - Ag composites for 24 or $48 \mathrm{~h}$ (Fig. 10). The results showed that the cell viability with $\mathrm{Ag}$ NPs was lower than that of the $\mathrm{SiO}_{2}$ nanospheres and $\mathrm{SiO}_{2}-\mathrm{Ag}$ composites after a $24 \mathrm{~h}$ culture. However, after

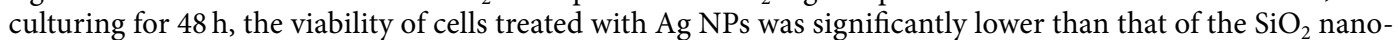
spheres and $\mathrm{SiO}_{2}-\mathrm{Ag}$ composites. Increasing the incubation time and concentration of the $\mathrm{Ag} \mathrm{NPs}$ resulted in a significant decrease in cell viability. In our study, the different results between the Xoo and rice cells might have occurred because the structure of bacteria and plant cells is different and the content of silver in the $\mathrm{SiO}_{2}-\mathrm{Ag}$ composites was low and had no impact on the rice cells. More detailed reasons require further study. Therefore, we anticipate that the $\mathrm{SiO}_{2}$ - $\mathrm{Ag}$ composites are promising antibacterial agents that would control rice diseases effectively and provide rice plants with nutrients.

In summary, we have developed a simple and environmentally friendly method using rice husks as a raw material to synthesize $\mathrm{SiO}_{2}$ nanospheres. These materials were then decorated with $\mathrm{Ag}$ NPs by the reduction of Ag ions in the presence of PVP as a stabilizer and reductant. TEM, SEM and XRD indicated that Ag NPs with small sizes were well dispersed onto the surface of $\mathrm{SiO}_{2}$ nanospheres. This structure could prevent the aggregation and oxidation of Ag NPs. We also confirmed that the $\mathrm{SiO}_{2}$ - Ag composites displayed antibacterial activity against Xoo that was approximately four times higher than that of the Ag NPs. Meanwhile, the antibacterial mechanism of the $\mathrm{SiO}_{2}$ - Ag composites was explored. The $\mathrm{Ag}$ ions released from the $\mathrm{SiO}_{2}-\mathrm{Ag}$ composites could induce the production of ROS, leading to the inhibition of DNA replication and disruption of the cell wall/membrane. More importantly, the cytotoxicity assay indicated that the $\mathrm{SiO}_{2}-\mathrm{Ag}$ composites showed only mild toxicity towards rice cells. Thus, the $\mathrm{SiO}_{2}-\mathrm{Ag}$ composites have a great potential application in rice disease management as antibacterial 

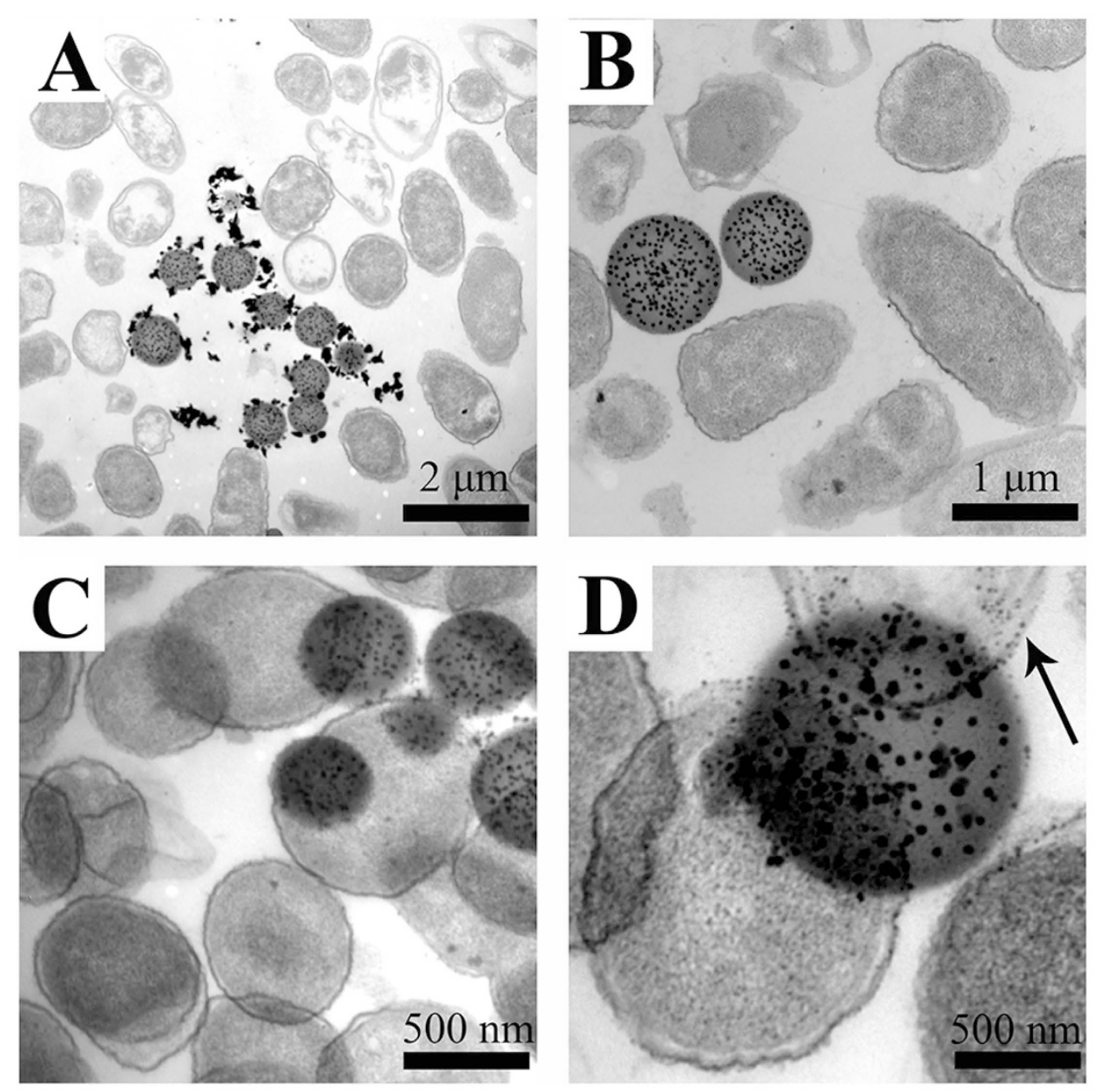

Figure 7. Typical TEM images of Xoo treated with $\mathrm{SiO}_{2}$-Ag composites.
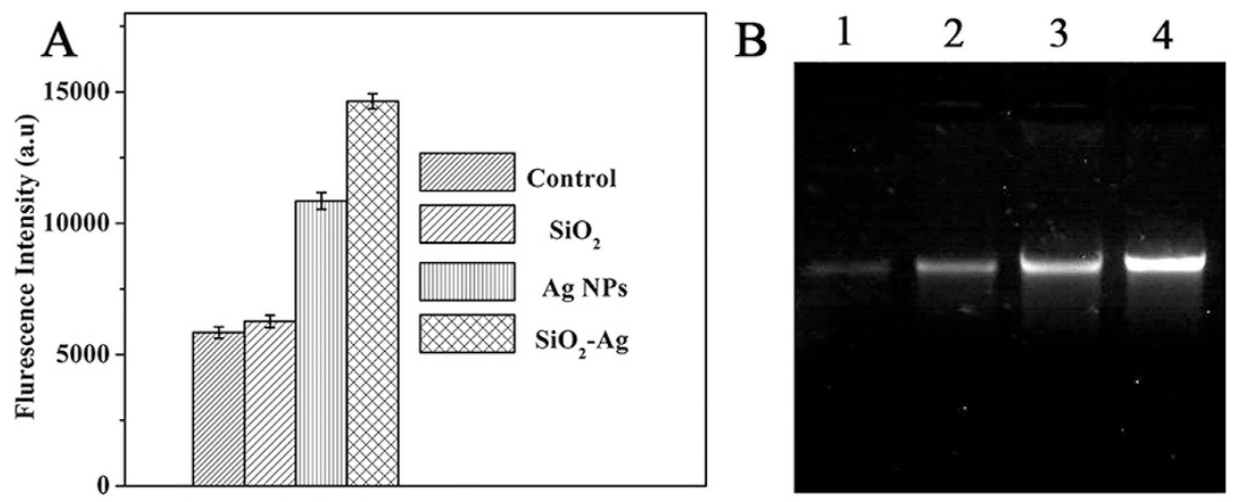

Figure 8. (A) Formation of ROS in Xoo cells after a $2 \mathrm{~h}$ incubation period with the control, $\mathrm{SiO}_{2}$ nanospheres, $\mathrm{Ag}$ NPs and the $\mathrm{SiO}_{2}-\mathrm{Ag}$ composites. ROS were detected by fluorescence measurement of the reporter DCF. Each data point represents the mean value from at least three independent experiments. (B) Electrophoresis analysis of genomic DNA in Xoo cells treated with different concentrations of the $\mathrm{SiO}_{2}-\mathrm{Ag}$ composites for $4 \mathrm{~h}$. Lanes 1, 2, 3 and 4 represent genomic DNA extracted from Xoo cells treated with 12.5, 3.2, 0.8 and $0 \mu \mathrm{g} / \mathrm{mL}$ of the $\mathrm{SiO}_{2}$ - Ag composites, respectively.

agents. This work provides a new strategy of environmentally friendly synthesis of antibacterial nanomaterials using residual biomass. 


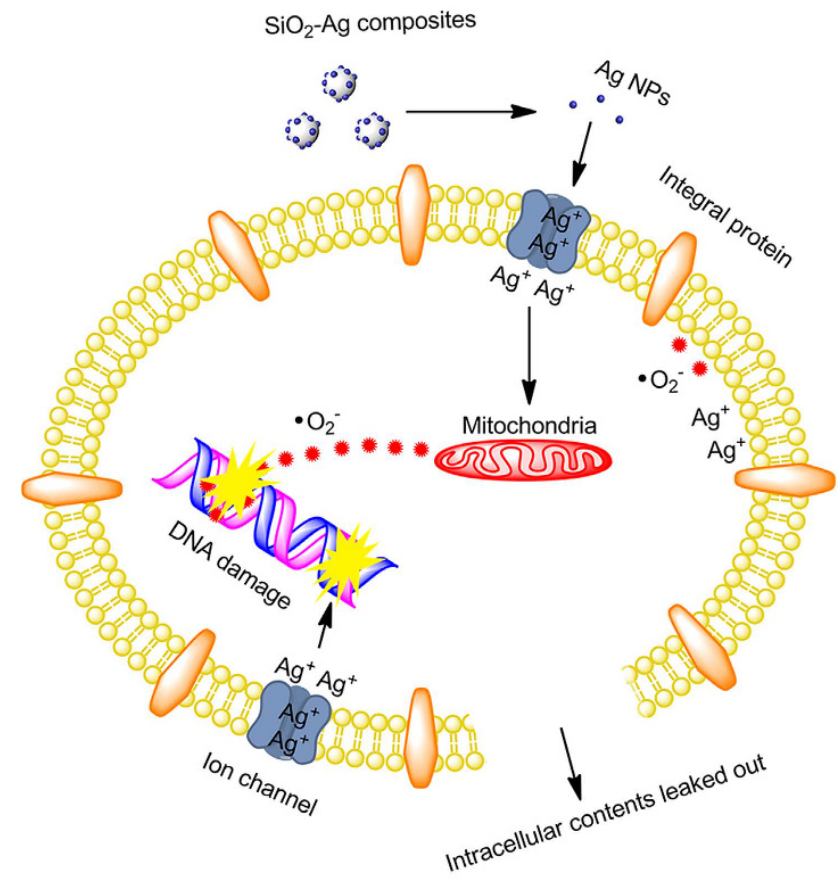

Figure 9. Schematic of the antibacterial mechanism of the $\mathrm{SiO}_{2}-\mathrm{Ag}$ composites.

\section{Methods}

Synthesis of $\mathrm{SiO}_{2}$ nanospheres. $\mathrm{SiO}_{2}$ nanospheres were synthesized using rice husks. The rice husks were washed with distilled water and milled into powder. Next, $2.0 \mathrm{M} \mathrm{NaOH}$ was mixed with the rice husk powder at a ratio of $1: 7(\mathrm{w} / \mathrm{v})$ in a $200 \mathrm{~mL}$ three-neck round-bottom flask equipped with a thermometer and heated to $100^{\circ} \mathrm{C}$ for $4 \mathrm{~h}$. The extract was separated from the solids by vacuum-assisted filtration and diluted with different volume ratios of distilled water and ethanol at $25^{\circ} \mathrm{C}$. Then, sulfuric acid $(1.0 \mathrm{M})$ was added drop-wise into the system until the $\mathrm{pH}$ of the system was approximately 9.0. Using an ultrasonicator, polyethylene glycol was completely dissolved into the solution, followed by the drop-wise addition of a solution of $1 \mathrm{M}$ sulfuric acid to lower the $\mathrm{pH}$ to 3. The mixture was left standing for $10 \mathrm{~min}$ at $25^{\circ} \mathrm{C}$ and then centrifuged for $5 \mathrm{~min}$. The products were washed several times with distilled water and dried at $60^{\circ} \mathrm{C}$ for $5 \mathrm{~h}$. To obtain the $\mathrm{SiO}_{2}$ nanospheres, the samples were calcined at $550^{\circ} \mathrm{C}$ for $1 \mathrm{~h}$ in a muffle furnace to remove residual organics in the $\mathrm{SiO}_{2}$ nanosphere sample.

Synthesis of $\mathrm{SiO}_{2}-\mathrm{Ag}$ composites. To form a homogeneous $\mathrm{SiO}_{2}-\mathrm{Ag}$ composite suspension, $100 \mathrm{mg}$ of the $\mathrm{SiO}_{2}$ nanosphere powder in $100 \mathrm{~mL}$ of deionized water was sonicated for $30 \mathrm{~min}$, and $6 \mathrm{~g} \mathrm{PVP}$ was dissolved in the previous solution. Then, $20 \mathrm{~mL}$ of an $\mathrm{AgNO}_{3}(1 \mathrm{mM})$ aqueous solution was rapidly added into the above solution. This mixture was stirred vigorously for $12 \mathrm{~h}$ in the dark at $80^{\circ} \mathrm{C}$. The resulting product was collected by centrifugation at 5,000 rpm for $10 \mathrm{~min}$ and further washed in deionized water several times to remove residual $\mathrm{Ag}$ ions. The dry $\mathrm{SiO}_{2}-\mathrm{Ag}$ composites were obtained after drying under vacuum for $3 \mathrm{~h}$ at $60^{\circ} \mathrm{C}$.

Characterization. The obtained samples were characterized by XRD performed on a X-ray diffractometer with a $\mathrm{Cu}$ target in the $2 \theta$ range from $5^{\circ}$ to $80^{\circ}(40 \mathrm{kV}, 30 \mathrm{~mA}, \lambda=1.54051 \AA)$. The surface morphologies of the samples were characterized by FEI Quanta 200 SEM. Morphological features of the $\mathrm{SiO}_{2}-\mathrm{Ag}$ composites were observed by a Philips TECNAI 10 TEM and a JEOL JEM-2100F field emission electron microscope equipped with Oxford INCA Energy TEM 200 EDS devices with an accelerating voltage of $200 \mathrm{kV}$. The concentration of silver was estimated using ICP-AES.

Release property. The concentrations of Ag ions released from the samples were monitored by ICP-AES. Approximately $1 \mathrm{mg}$ of $\mathrm{Ag} \mathrm{NPs}$, the $\mathrm{SiO}_{2}$ - $\mathrm{Ag}$ composite solid and the same equivalent amount of $\mathrm{AgNO}_{3}$ were immersed in $5 \mathrm{~mL}$ of ultrapure water on a slow shaking incubator at $37^{\circ} \mathrm{C}$. After $1 \mathrm{~d}$, the concentrations of Ag ions were measured, and the solutions were transferred into dialysis tubes and immersed in $100 \mathrm{~mL}$ of ultrapure water every $5 \mathrm{~d}$. The concentration of Ag ions in the ultrapure water solutions was measured by ICP-AES.

Antibacterial activity. Before the experiment, petri dishes and solid Luria-Bertani (LB) medium must be sterilized in an autoclave at $121^{\circ} \mathrm{C}$ for $20 \mathrm{~min}$. The antibacterial properties of the $\mathrm{Ag} \mathrm{NPs}$ and $\mathrm{SiO}_{2}-\mathrm{Ag}$ composites were evaluated by testing the disk diffusion inhibitory zone and minimum inhibitory concentration breakpoints.

Disk diffusion inhibition zone. In this test, we adjusted the concentration of the bacterial suspension until the optical density was approximately 0.1 at $600 \mathrm{~nm}$. The concentrations of $\mathrm{Ag} \mathrm{NPs}$ and $\mathrm{SiO}_{2}-\mathrm{Ag}$ composites were $200 \mu \mathrm{g} / \mathrm{mL}$. The standard small piece of filter paper $(6 \mathrm{~mm})$ containing $\mathrm{SiO}_{2}$ nanospheres, $\mathrm{Ag} \mathrm{NPs}$ and $\mathrm{SiO}_{2}-\mathrm{Ag}$ 

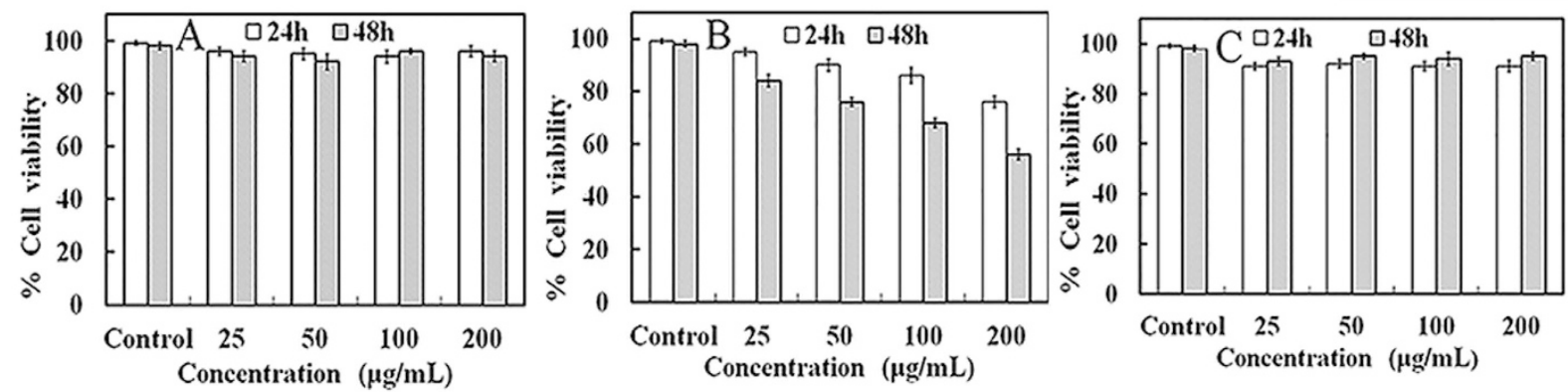

Figure 10. Cell viability assay for Xoo cells. Influence of different concentrations of $\mathrm{SiO}_{2}(\mathbf{A}), \mathrm{Ag} \mathrm{NPs}$ (B) and $\mathrm{SiO}_{2}-\mathrm{Ag}$ composites $(\mathbf{C})$ on rice cell viability. Each data point represents the mean value from at least three independent experiments.

composites were placed onto LB agar plates swabbed with bacteria. The plates were incubated for $16 \mathrm{~h}$, and the zone of inhibition of bacterial growth was used as a measurement of susceptibility. Sensitivity was inversely proportional to the diameter of the zone.

Minimum inhibitory concentration (MIC). The MIC was determined by the lowest concentrations of Ag NPs and $\mathrm{SiO}_{2}$ - Ag composites that restrain bacteria growth after overnight incubation. First, the bacteria were incubated at $37^{\circ} \mathrm{C}$ for $12 \mathrm{~h}$ in LB liquid medium, and the bacterial solution was diluted with LB to an optical density of 0.1 at $600 \mathrm{~nm}$. The $\mathrm{Ag} \mathrm{NPs}$ and $\mathrm{SiO}_{2}-\mathrm{Ag}$ composite solutions with different concentrations $(0,0.05,0.1,0.2,0.4,0.8$, $1.6,3.2,6.25,12.5,25,50,100$ and $200 \mu \mathrm{g} / \mathrm{mL})$ were prepared. Then, the bacterial solution $(100 \mu \mathrm{L})$ and $0.9 \mathrm{~mL}$ of $\mathrm{LB}$ liquid medium were added to $1 \mathrm{~mL}$ of each of the different concentrations of $\mathrm{Ag} \mathrm{NPs}$ and $\mathrm{SiO}_{2}-\mathrm{Ag}$ composite solutions, and these solutions were placed onto a rotary shaker at $120 \mathrm{rpm}$ at $37^{\circ} \mathrm{C}$ for $2 \mathrm{~h}$. After that, $100 \mu \mathrm{L}$ of the bacterial solution was added to each agar plate and spread evenly. Later on, all of the agar plates were sealed with parafilm and incubated at $37^{\circ} \mathrm{C}$ for $18 \mathrm{~h}$. Finally, the MIC was determined by the lowest concentrations of Ag NPs and $\mathrm{SiO}_{2}$-Ag composites that inhibited the visible growth of bacteria ${ }^{46}$.

Fluorescence imaging. Bacteria were incubated in the $\mathrm{LB}$ liquid medium supplemented with $\mathrm{SiO}_{2}$ nanospheres, Ag NPs and the $\mathrm{SiO}_{2}$-Ag composites. The bacterial cells were collected by centrifugation and washed three times with phosphate buffer saline (PBS) and then stained using EB and AO for $15 \mathrm{~min}$. After washing with PBS, the samples were observed by fluorescence microscopy.

Cell morphological change. To observe the morphological changes of bacterial cells after treatment with the $\mathrm{SiO}_{2}$-Ag composites, the Xoo cells were exposed to the $\mathrm{SiO}_{2}-\mathrm{Ag}$ composites $(12.5 \mu \mathrm{g} / \mathrm{mL})$ in microtiter plates with silicon chips in the bottom. After the cultures grew for $2 \mathrm{~h}$, the silicon chip was harvested and processed for TEM. First, the silicon chip was removed from the microtiter plates and washed three times with buffer. Then, the samples were fixed in $2.5 \%$ glutaraldehyde for $2 \mathrm{~h}$. After fixation, the silicon chip was rinsed with buffer twice. The samples were washed with a cacodylate buffer and fixed in $1 \%$ osmium tetraoxide. Then, sample embedding was carried out using a standard protocol. The slices were deposited on bare \#200 mesh grids and stained with uranyl acetate for $5 \mathrm{~min}$. Finally, the grids were dried in a desiccator and examined using TEM.

Intracellular reactive oxygen species measurement. 2,7-dichlorofluoroscein diacetate (DCFH-DA) was used to further identify the intracellular generation of ROS in the treated bacterial cells. The DCFH-DA could enter the cell and react with ROS, which formed the highly fluorescent compound dichlorofluorescein (DCF). Experimental procedures were followed as described previously ${ }^{41,47}$. The fluorescent signal intensity of DCF (with an emission wavelength of $525 \mathrm{~nm}$ ) was recorded using a fluorescence spectrophotometer with an excitation wavelength of $488 \mathrm{~nm}$.

Genomic DNA isolation. The genomic DNA was extracted from the Xoo cells treated with different concentrations of $\mathrm{SiO}_{2}$-Ag composite $(12.5,3.2,0.8 \mu \mathrm{g} / \mathrm{mL})$ for $4 \mathrm{~h}$. Then, the DNA was isolated by the phenol chloroform extraction method ${ }^{48}$. The isolated DNA was then analyzed on a $1 \%$ agarose gel using EB.

Cytotoxicity assay. Rice suspension cells were cultured according to the literature procedure ${ }^{49}$. The seeds were surface-sterilized in $75 \%$ ethanol for $1 \mathrm{~min}$ and $0.1 \%$ mercury chloride for $10 \mathrm{~min}$ and rinsed five times with sterile distilled water. The seeds were incubated in plastic petri dishes containing modified N6 medium. The sealed dishes were cultured in the dark to induce calli from mature rice seeds at $28^{\circ} \mathrm{C}$. Every $7 \mathrm{~d}$, the calli were subcultured in the subculture medium. After 4 weeks, the calli were transferred to $125 \mathrm{~mL}$ conical flasks containing $40 \mathrm{~mL}$ of liquid AA medium and placed on a rotary shaker at $110 \mathrm{rpm}$ at $28^{\circ} \mathrm{C}$ in the dark. To supplement nutrients, the suspension cells were subcultured at $5 \mathrm{~d}$ intervals for 2-3 months by replacing the old nutrient solution medium every $5 \mathrm{~d}$.

Then, the culture medium was replaced with $100 \mu \mathrm{L}$ of different concentrations of $\mathrm{SiO}_{2}$ nanospheres, Ag NPs or the $\mathrm{SiO}_{2}-\mathrm{Ag}$ composites. The cells were further incubated for 24 or $48 \mathrm{~h}$, and then, $25 \mu \mathrm{L}$ of MTT 
(3-(4,5-dimethyl-2-yl)-2,5-diphenyl tetrazolium bromide) $(5 \mathrm{mg} / \mathrm{mL})$ was added to each culture medium until the final concentration was $1 \mu \mathrm{g} / \mathrm{mL}$. After incubation for another $2 \mathrm{~h}$, the absorbance was measured at $570 \mathrm{~nm}$ using a microplate reader. Cell viability was normalized to that of rice cells cultured in the cell media. Measurements were repeated three times for each concentration.

\section{References}

1. Yu, G., Olsen, K. M. \& Schaal, B. A. Molecular evolution of the endosperm starch synthesis pathway genes in rice (Oryza sativa L.) and its wild ancestor, O. rufipogon L. Mol. Bio. Evol. 28, 659-671 (2011).

2. Wu, L. et al. Difficidin and bacilysin from Bacillus amyloliquefaciens FZB42 have antibacterial activity against Xanthomonas oryzae rice pathogens. Sci. Rep. 5, 12975, doi: 10.1038/srep12975 (2015).

3. Mew, T. Current status and future prospects of research on bacterial blight of rice. Annu. Rev. Phytopathol. 25, 359-382 (1987).

4. Wiwattanapatapee, R. et al. Floating pellets containing bacterial antagonist for control sheath blight of rice: formulations, viability and bacterial release studies. J. Control. Release 95, 455-462 (2004).

5. Dean, R. A. et al. The genome sequence of the rice blast fungus Magnaporthe grisea. Nature 434, 980-986 (2005).

6. Mizukami, T. \& Wakimoto, S. Epidemiology and control of bacterial leaf blight of rice. Annu. Rev. Phytopathol. 7, 51-72 (1969).

7. Li, P. et al. Design, synthesis, and antibacterial activity against rice bacterial leaf blight and leaf streak of 2, 5-substituted-1, 3, 4-oxadiazole/thiadiazole sulfone derivative. Bioorg. Med. Chem. Lett. 24, 1677-1680 (2014).

8. Ocsoy, I. et al. Nanotechnology in Plant Disease Management DNA-Directed Silver Nanoparticles on Graphene Oxide as an Antibacterial against Xanthomonas perforans. ACS Nano 7, 8972-8980 (2013).

9. Wang, X., Liu, X., Chen, J., Han, H. \& Yuan, Z. Evaluation and mechanism of antifungal effects of carbon nanomaterials in controlling plant fungal pathogen. Carbon 68, 798-806 (2014).

10. Chen, J. et al. Graphene oxide exhibits broad-spectrum antimicrobial activity against bacterial phytopathogens and fungal conidia by intertwining and membrane perturbation. Nanoscale 6, 1879-1889 (2014).

11. Rao, K. J. \& Paria, S. Use of sulfur nanoparticles as a green pesticide on Fusarium solani and Venturia inaequalis phytopathogens. RSC Adv. 3, 10471-10478 (2013).

12. Sunada, K., Kikuchi, Y., Hashimoto, K. \& Fujishima, A. Bactericidal and detoxification effects of TiO2 thin film photocatalysts. Environ. Sci. Technol. 32, 726-728 (1998).

13. Dimkpa, C. O., McLean, J. E., Britt, D. W. \& Anderson, A. J. Antifungal activity of ZnO nanoparticles and their interactive effect with a biocontrol bacterium on growth antagonism of the plant pathogen Fusarium graminearum. BioMetals 26, 913-924 (2013).

14. Young, M. \& Santra, S. Copper $(\mathrm{Cu})$-Silica nanocomposite containing valence-engineered Cu: a new strategy for improving the antimicrobial efficacy of Cu biocides. J. Agric. Food. Chem. 62, 6043-6052 (2014).

15. Yang, Y. et al. Pyrosequencing reveals higher impact of silver nanoparticles than $\mathrm{Ag}^{+}$on the microbial community structure of activated sludge. Water Res. 48, 317-325 (2014).

16. Xiu, Z.-m., Zhang, Q.-b., Puppala, H. L., Colvin, V. L. \& Alvarez, P. J. Negligible particle-specific antibacterial activity of silver nanoparticles. Nano Lett. 12, 4271-4275 (2012).

17. Kvitek, L. et al. Effect of surfactants and polymers on stability and antibacterial activity of silver nanoparticles (NPs). J. Phys. Chem. C 112, 5825-5834 (2008).

18. El Badawy, A. M. et al. Surface charge-dependent toxicity of silver nanoparticles. Environ. Sci. Technol. 45, 283-287 (2010).

19. Zhang, H., Smith, J. A. \& Oyanedel-Craver, V. The effect of natural water conditions on the anti-bacterial performance and stability of silver nanoparticles capped with different polymers. Water Res. 46, 691-699 (2012).

20. Wang, J. et al. Phytostimulation of poplars and Arabidopsis exposed to silver nanoparticles and $\mathrm{Ag}^{+}$at sublethal concentrations. Environ. Sci. Technol. 47, 5442-5449 (2013).

21. Dietz, K. J. \& Herth, S. Plant nanotoxicology. Trends Plant Sci. 16, 582-589 (2011).

22. LeeáTan, K. Growth of Pd, Pt, Ag and Au nanoparticles on carbon nanotubes. J. Mater. Chem. 11, 2378-2381 (2001).

23. Shi, Z. et al. Enhanced colloidal stability and antibacterial performance of silver nanoparticles/cellulose nanocrystal hybrids. J. Mater. Chem. B 3, 603-611 (2015)

24. Zhou, Y. et al. Highly stable and dispersive silver nanoparticle-graphene composites by a simple and low-energy-consuming approach and their antimicrobial activity. Small 9, 3445-3454 (2013).

25. Cui, J. et al. Facile fabrication of carbonaceous nanospheres loaded with silver nanoparticles as antibacterial materials. J. Mater. Chem. 22, 8121-8126 (2012).

26. Cui, J., Yang, Y., Hu, Y. \& Li, F. Rice husk based porous carbon loaded with silver nanoparticles by a simple and cost-effective approach and their antibacterial activity. J. Colloid Interface Sci. 455, 117-124 (2015).

27. Tuck, C. O., Pérez, E., Horváth, I. T., Sheldon, R. A. \& Poliakoff, M. Valorization of biomass: deriving more value from waste. Science 337, 695-699 (2012).

28. Vaibhav, V., Vijayalakshmi, U. \& Roopan, S. M. Agricultural waste as a source for the production of silica nanoparticles. Spectrochim. Acta A 139, 515-520 (2015).

29. Liu, C. et al. Foliar application of two silica sols reduced cadmium accumulation in rice grains. J. Hazardous Mater. 161, 1466-1472, (2009).

30. Liu, C., Wei, L., Zhang, S., Xu, X. \& Li, F. Effects of nanoscale silica sol foliar application on arsenic uptake, distribution and oxidative damage defense in rice (Oryza sativa L.) under arsenic stress. RSC Adv. 4, 57227-57234 (2014).

31. Tang, L. \& Cheng, J. Nonporous silica nanoparticles for nanomedicine application. Nano Today 8, 290-312 (2013).

32. Morones, J. R. et al. The bactericidal effect of silver nanoparticles. Nanotechnology 16, 2346-2353 (2005).

33. Raimondi, F., Scherer, G. G., Kötz, R. \& Wokaun, A. Nanoparticles in energy technology: examples from electrochemistry and catalysis. Angew. Chem. Int. Ed. 44, 2190-2209 (2005).

34. Chen, R., Xu, D., Guo, G. \& Gui, L. Silver telluride nanowires prepared by dc electrodeposition in porous anodic alumina templates. J. Mater. Chem. 12, 2435-2438 (2002).

35. Zhang, Z. et al. A facile one-pot method to high-quality Ag-graphene composite nanosheets for efficient surface-enhanced Raman scattering. Chem. Commun. 47, 6440-6442 (2011).

36. Kittler, S., Greulich, C., Diendorf, J., Koller, M. \& Epple, M. Toxicity of silver nanoparticles increases during storage because of slow dissolution under release of silver ions. Chem. Mater. 22, 4548-4554 (2010).

37. Gao, N., Chen, Y. \& Jiang, J. Ag@ $\mathrm{Fe}_{2} \mathrm{O}_{3}$-GO nanocomposites prepared by a phase transfer method with long-term antibacterial property. ACS Appl. Mater. Inter. 5, 11307-11314 (2013).

38. Das, S. K. et al. Nano-silica fabricated with silver nanoparticles: antifouling adsorbent for efficient dye removal, effective water disinfection and biofouling control. Nanoscale 5, 5549-5560 (2013)

39. Cai, X. et al. The use of polyethyleneimine-modified reduced graphene oxide as a substrate for silver nanoparticles to produce a material with lower cytotoxicity and long-term antibacterial activity. Carbon 50, 3407-3415 (2012).

40. Leung, Y. H. et al. Mechanisms of antibacterial activity of MgO: non-ROS mediated toxicity of MgO nanoparticles towards Escherichia coli. Small 10, 1171-1183 (2014).

41. Applerot, G. et al. Understanding the antibacterial mechanism of $\mathrm{CuO}$ nanoparticles: revealing the route of induced oxidative stress. Small 8, 3326-3337 (2012). 
42. Horst, A. M., Vukanti, R., Priester, J. H. \& Holden, P. A. An assessment of fluorescence- and absorbance-based assays to study metaloxide nanoparticle ROS production and effects on bacterial membranes. Small 9, 1753-1764 (2013).

43. Michal Natan, O. G., Ronit Lavi, Shlomo Margel and Ehud, Banin. Killing mechanism of stable N-Halamine cross-linked polymethacrylamide nanoparticles that selectively target bacteria. ACS Nano 9, 1175-1188 (2015).

44. Matai, I. et al. Antibacterial activity and mechanism of Ag-ZnO nanocomposite on S. aureus and GFP-expressing antibiotic resistant E. coli. Colloids Surf. B 115, 359-367 (2014).

45. Parandhaman, T. et al. Antimicrobial behavior of biosynthesized silica-silver nanocomposite for water disinfection: a mechanistic perspective. J. Hazard. Mater. 290, 117-126 (2015).

46. Yang, X. et al. Antibacterial activity of two-dimensional $\mathrm{MoS}_{2}$ sheets. Nanoscale 6, 10126-10133 (2014).

47. Yang Li, Z. W., Junfeng, Niu \& Yongsheng, Chen. Mechanism of Photogenerated Reactive Oxygen Species and Correlation with the Antibacterial Properties of Engineered Metal-Oxide Nanoparticlesk. ACS Nano 6, 5164-5173 (2012).

48. Raeder, U. \& Broda, P. Rapid preparation of DNA from filamentous fungi. Lett. Appl. Microbiol. 1, 17-20 (1985).

49. Chu, C. C. Establishment of an efficient medium for anther culture of rice through comparative experiments on the nitrogen sources. Sci. Sin. 18, 659-668 (1975).

\section{Acknowledgements}

This work was supported by the National Natural Science Foundation of China (Grant No. 41401564), Natural Science Foundation of Guangdong Province, China (No. 2012B010200030 and 2014A030313706) and Science and Technology Program of Guangzhou, China (201510010259).

\section{Author Contributions}

J.H.C. conceived the research, D.S.Y. and Y.L.L. designed the experiments, J.H.C. and Y.L. performed the experiments and collected the experimental data, J.H.C wrote the manuscript. All authors reviewed the manuscript.

\section{Additional Information}

Supplementary information accompanies this paper at http://www.nature.com/srep

Competing financial interests: The authors declare no competing financial interests.

How to cite this article: Cui, J. et al. Facile fabrication of rice husk based silicon dioxide nanospheres loaded with silver nanoparticles as a rice antibacterial agent. Sci. Rep. 6, 21423; doi: 10.1038/srep21423 (2016).

(c) (i) This work is licensed under a Creative Commons Attribution 4.0 International License. The images or other third party material in this article are included in the article's Creative Commons license, unless indicated otherwise in the credit line; if the material is not included under the Creative Commons license, users will need to obtain permission from the license holder to reproduce the material. To view a copy of this license, visit http://creativecommons.org/licenses/by/4.0/ 